\title{
ANALISIS BEHAVIORAL INTENTION PADA LAYANAN APLIKASI RCTI+
}

\author{
Anggit Mardiana Permatasari \\ Program Studi Magister Manajemen Universitas Tarumanagara \\ anggitmardiana@gmail.com \\ Hetty Karunia Tunjungsari \\ Program Studi Magister Manajemen Universitas Tarumanagara
}

Masuk : 06-12-2019, revisi : 31-01-2020 diterima untuk diterbitkan : 01-02-2020

\begin{abstract}
The current era is called the information age, where humans really need information. The existence of the internet on smartphones makes it easier for humans to get information and enjoy content wherever and whenever. One of the content services in Indonesia is the MNC Group's RCTI + application. Although RCTI + is a new company, RCTI + has an active number of users of 302,569 until November 2019. RCTI + has a fairly high market share because the digital era is growing rapidly. This study measures the interest of users of RCTI + applications in Indonesia by using a modified UTAUT2 research model, where researchers analyze the variables Performance Expectancy, Effort Expectancy, Social Influence, Facilitating Conditions, Hedonic Motivation, Habit, and Content on Behavioral Intention. The data used in this study were 89 valid respondents obtained online using a questionnaire. Respondents are users of the RCTI + application. Researchers used Structural Equation Modeling (SEM) with SmartPLS software version 3.0 to test hypotheses. The results showed that Performance Expectancy, Effort Expectancy, Social Influence, Facilitating Conditions, Habit and Content had an influence on Behavioral Intention. However, Hedonic Motivations has a negative influence on Behavioral Intention. The Age variable as a moderator variable influences Content on Behavioral Intention, while Gender has no effect. This study resulted in an R2 of 0,900 and included in the moderate category. This research, has found that the variable that most influences Behavioral Intention is Habit.
\end{abstract}

Keywords : UTAUT 2, Consumer Behavior, RCTI+

\begin{abstract}
Abstrak : Era masa kini disebut sebagai era informasi, dimana manusia sangat membutuhkan informasi. Adanya internet pada ponsel pintar (smartphone) semakin memudahkan manusia untuk mendapatkan informasi maupun menikmati konten dimanapun dan kapanpun. Salah satu layanan konten di Indonesia ialah aplikasi RCTI+ milik MNC Group. Meskipun RCTI+ merupakan perusahaan baru, namun RCTI+ memiliki jumlah pengguna aktif sebesar 302.569 hingga November 2019. RCTI+ memiliki pangsa pasar cukup tinggi karena era digital sangat berkembang pesat. Penelitian ini mengukur minat pengguna aplikasi RCTI+ di Indonesia dengan menggunakan model penelitian UTAUT2 yang telah dimodifikasi, dimana peneliti menganalisis variabel Performance Expectancy, Effort Expectancy, Social Influence, Facilitating Condition, Hedonic Motivation, Habit, dan Content terhadap Behavioral Intention. Data yang digunakan dalam penelitian ini sebanyak 89 responden valid yang didapatkan melalui online menggunakan kuesioner. Responden merupakan pengguna aplikasi RCTI+. Peneliti menggunakan Structural Equation Modeling (SEM) dengan software SmartPLS versi 3.0 untuk menguji hipotesis. Hasil penelitian menunjukkan bahwa Performance Expectancy, Effort Expectancy, Social Influence, Facilitating Conditions, Habit dan Content memiliki pengaruh terhadap Behavioral Intention. Namun, Hedonic Motivations memiliki pengaruh negatif terhadap Behavioral Intention. Variabel Age (Usia) sebagai variabel moderator memengaruhi Content terhadap Behavioral Intention, sedangkan Gender tidak berpengaruh. Penelitian ini menghasilkan nilai $\mathrm{R}^{2}$ sebesar 0,900 dan termasuk kategori
\end{abstract}


moderat. Penelitian ini, telah menemukan bahwa variabel yang paling berpengaruh terhadap Behavioral Intention ialah Habit.

Kata kunci : UTAUT 2, Perilaku Konsumen, RCTI+

\section{PENDAHULUAN}

Perkembangan jaman terus bergulir cepat didampingi oleh berkembangnya teknologiteknologi modern berbasis internet. Era masa kini seringkali disebut juga era informasi, dimana manusia mengutamakan informasi. Informasi kini telah melekat menjadi suatu kebutuhan manusia. Kebutuhan ini mampu memicu adanya perkembangan yang hadir dari teknologi komunikasi. Hal ini ditandai dengan semakin lumrahnya penggunaan internet di berbagai aktivitas. Pengguna aktif internet khususnya di kalangan milenial sendiri mencapai 94,4\%, berdasarkan data yang diperoleh IDN Research Institute pada Indonesia Milenial Report 2019.

Adanya internet didukung dengan adanya ponsel pintar (smartphone) yang membuat manusia semakin mudah serta merasa bebas untuk memilih informasi yang diinginkan, salah satunya dengan kemudahan untuk menikmati konten hiburan dimanapun dan kapanpun dengan perangkat yang dimiliki. Hal ini juga dibuktikan oleh IDN Research Institute dalam Indonesia Milenial Report 2019 bahwa 4 aktivitas utama ketika seseorang terkoneksi dengan internet adalah chatting/messaging (saling berkirim pesan singkat), browsing (berselancar mencari informasi di dunia maya), social networking (memperluas jaringan sosial dengan memanfaatkan media sosial) dan video streaming (layanan tontonan berupa video yang diakses dengan menggunakan internet).

Layanan video streaming kini semakin popular diberbagai kalangan karena dapat diakses dengan mudah, kapanpun dan dimanapun juga. Hampir semua orang mampu mengakses layanan video melalui internet untuk mengisi waktu serta mencari hiburan maupun informasi yang dibutuhkan.

Tingginya penggunaan ponsel oleh manusia untuk mengakses video dengan bantuan koneksi internet ditunjukkan oleh dailysocial.id (2018). Hal ini mendorong banyak perusahaan berlomba-lomba untuk membuat sebuah layanan berbasis video on demand maupun video streaming, salah satunya dengan peluncuran sebuah aplikasi yang berisi video streaming, video on demand, artikel menarik serta masih banyak lagi. Aplikasi yang mampu menyajikan ragam informasi serta hiburan untuk masyarakat Indonesia.

MNC Group meluncurkan sebuah aplikasi OTT terbaru bernama RCTI+. RCTI+ merupakan layanan aplikasi video on demand dan live streaming serta layanan informasi terbaru dari MNC pada lini konten digital. Melalui aplikasi ini pengguna dapat mencari berbagai informasi dan juga hiburan hanya dalam satu genggaman. Sesuai dengan tagline RCTI+ "Nonton Ga Monoton" membuat aplikasi ini juga menghadirkan konten lawas serta banyak konten eksklusif lainnya. Adanya aplikasi baru ini membuat peneliti tertarik untuk melakukan penilitian dengan judul "Analisis Faktor-Faktor Willingness to View pada Layanan Aplikasi RCTI+."

Persaingan media era masa kini mulai panas, untuk itu perusahaan harus mengetahui faktor apa saja yang dapat memengaruhi minat menonton konsumen. Dalam penelitian ini, peneliti memiliki rasa ingin tahu terhadap faktor-faktor yang memengaruhi pengguna aplikasi RCTI+ berdasarkan Behavioral Intention dengan menggunakan model UTAUT 2 yang dimodifikasi.

Tujuan dari penelitian ini yakni mengetahui faktor-faktor willingness to view pada layanan aplikasi RCTI+.

\section{MODEL UTAUT 2}

Unified Theory of Acceptance and Use of Technology 2 atau yang biasa disingkat menjadi UTAUT 2 adalah model pengembangan dari UTAUT yang dari awal diperkenalkan oleh Venkatesh, Thong dan juga Xu di tahun 2012 (Indrawati, 2012:35). Venkatesh (2012:172-173) 
menyatakan bahwa UTAUT 2 adalah model yang tidak hanya menggabungkan hubungan utama pada UTAUT, namun model ini juga menambahkan new construcs dan hubungan dalam memperluas penerapannya pada konteks konsumen. Salah satu survei online dua tahap dilakukan oleh Venkatesh, et al. (2012) terhadap 1.512 orang konsumen internet mobile. Secara impiris Venkatesh membuktikan bahwa model UTAUT 2 mempunyai tingkat aplikabilitas terhadap konteks konsumen. Dibuktikan pula bahwa UTAUT 2 menunjukkan adanya peningkatan substansial pada varians, dimana Behavioral Intention meningkat menjadi $74 \%$ serta Technology Use sebesar 52\%, dimana pada model sebelumnya yakni UTAUT sebesar $56 \%$ dan juga 40\%. Hal ini sebagai bukti bahwa UTAUT 2 merupakan model yang lebih kritis dalam hal perkiraan validitas jika konteksnya ialah konsumen, jika dibandingkan dengan model UTAUT orisinil dimana konteksnya adalah organisasi.

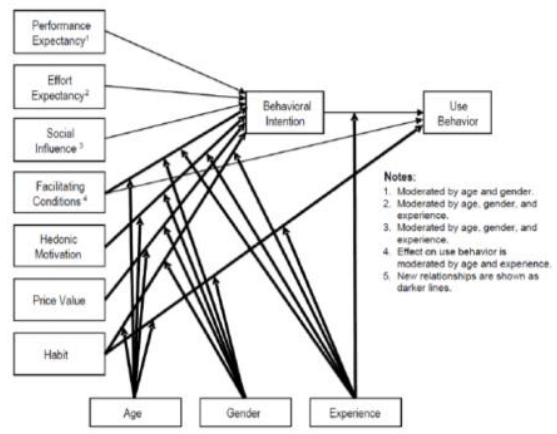

\section{Model Unified Theory of Acceptance and Use of Technology 2}

Sumber: Venkatesh, et al. (2012)

Dalam penelitian selanjutnya, Venkatesh, et al. (2012) menambah variabel-variabel baru ke dalam model UTAUT orisinil yang telah diteliti sebelumnya sebanyak tiga variabel. Tiga variabel tersebut adalah Price Value, Hedonic Motivation, dan Habit. Fungsi dari penambahan variabel-variabel tersebut ialah peningkatan kemampuan model untuk memprediksi Behavioral Intention pada penggunaan teknologi karena model UTAUT memiliki konteks organisasi. Variabel-variabel tersebut adalah Performance Expectancy, Effort Expectancy, Social Influence, Facilitating Conditions, Hedonic Motivations, Price Value, Habit, Behavioral Intention dan Use Behavior.

Pada penelitian ini peneliti menggunakan model penelitian UTAUT2 yang telah diteliti oleh Venkatesh, et al. (2012) sebagai model dasar, model UTAUT2 adalah model terbaru dalam teori adopsi teknologi. Berdasarkan sumber-sumber teori yang didapat, maka dapat disimpulkan kerangka pemikiran dari penelitian ini adalah sebagai berikut :

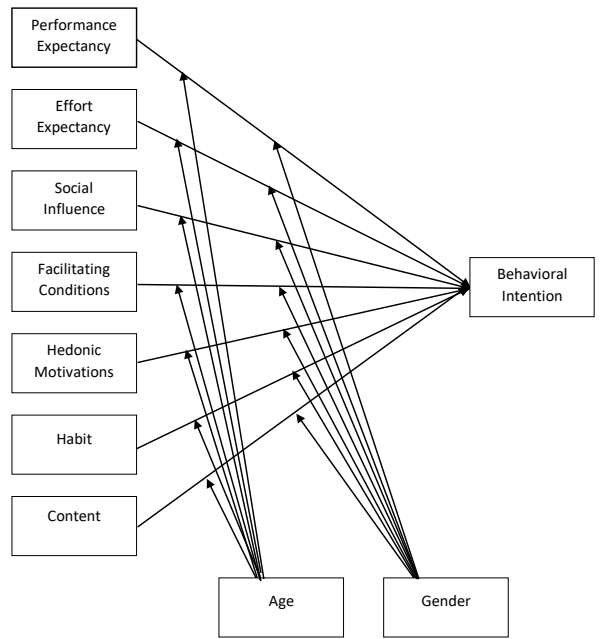

Sumber: Hasil Olahan Peneliti (2019) 


\section{METODE PENELITIAN}

Penelitian ini menggunakan teknik survei melalui penyebaran kuesioner sebagai teknik pengumpulan data. Sugiyono (2012) mengatakan bahwa teknik pengumpulan data yang dilakukan dengan cara memberi seperangkat pertanyaan tertulis kepada responden yang berhubungan langsung mengenai masalah yang akan diteliti dan responden akan menjawab pertanyaan-pertanyaan tersebut.

Populasi dalam penelitian ini yakni jumlah seluruh pengguna aplikasi RCTI+ di Indonesia. Penentuan sampel yang diambil dalam penelitian ini dibutuhkan teknik suatu teknik yang disebut teknik sampling. Penelitian ini dalam pengambilan sampling menggunakan teknik nonprobability sampling. Selain menggunakan teknik sampling nonprobability sampling, penelitian ini juga menggunakan Sampling Purposive, dimana sampling purposive adalah teknik penentuan sampel dengan pertimbangan tertentu (Sugiyono, 2014). Dalam penelitian ini, bertujuan untuk mengetahui faktor-faktor yang memengaruhi pembentukan minat menonton pada layanan aplikasi RCTI+, sehingga sampel dalam penelitian ini ialah pengguna aplikasi RCTI+.

Banyak asumsi yang menyatakan bahwa pada analisis Structural Equation Modeling (SEM) membutuhkan ukuran sampel minimal 10 kali banyaknya indikator serta data harus berdistribusi normal. Dalam perkembangannya, sebuah metode SEM tidak memutuhkan asumsi tersebut yang dikenal dengan motole analisis Partial Least Square (PLS). Metode ini adalah analisis SEM berbasis varian yakni SEM - PLS. Parameter ini tidak membutuhkan ukuran sampel yang besar dan data tidak harus berdistribusi normal. Metode SEM-PLS dapat digunakan pada ukuran sampel kecil untuk menganalisa data dengan jenis skala likert relatif kecil. Nilai $\mathrm{R}^{2}$ pada sampel 50 dan sampel 160 sama baiknya dalam menguji kebaikan model. Hal ini menunjukkan bahwa SEM-PLS dapat mempermudah peneliti dalam melakukan penelitian (Ulum, et al., 2014). Dalam penelitian ini, peneliti mendapat 89 koresponden.

Teknik analisis data yang digunakan dalam penelitian ini adalah analisis deskriptif serta model persamaan structural atau SEM, menggunakan software SmartPLS 3.0.

\section{HASIL DAN PEMBAHASAN}

\section{Uji Analisis Deskriptif}

Persentase pengguna aplikasi RCTI+ berjenis kelamin laki-laki lebih banyak dengan angka $63,0 \%$, dengan total responden 56 orang, dimana jenis kelamin perempuan lebih sedikit dengan presentase $37,0 \%$, dengan total responden 33 orang. Variabel dengan skor tertinggi adalah variabel Effort Expectancy dengan angka 79,90\%, dimana peringkat ke dua dan ke tiga adalah variabel Falicitating Condition dengan angka 77,00\%, dan variabel Performance Expectancy dengan $76,80 \%$, dimana ketiga variabel tersebut ada pada kategori Tinggi, dan variabel yang mendapatkan skor terendah adalah variabel Habit. 7 dari 8 variabel dalam penelitan ini, masuk dalam kategori Tinggi, dimana 1 variabel lainnya masuk dalam kategori Cukup Tinggi.

\section{Pengujian Model Pengukuran}

AVE digunakan untuk mengukur suatu variabel bersatu atau variabel yang berkorelasi, dengan membandingkan variabel tersebut dengan item- item untuk mengukur variabel lain dalam suatu model (Indrawati, 2017:70). Hasil AVE (Average Variance Extracted) setiap variabel dalam penelitian ini, terdapat pada tabel 4.20 dibawah ini: 
Tabel 1

Nilai AVE (Average Variance Extracted)

\begin{tabular}{|c|c|}
\hline Variabel Laten & $\begin{array}{c}\text { Nilai AVE (Average } \\
\text { Variance Extracted) }\end{array}$ \\
\hline Performance Expectancy & 0,767 \\
\hline Effort Expectancy & 0,767 \\
\hline Social Influence & 0,806 \\
\hline Facilitating Conditions & 0,677 \\
\hline Hedonic Motivations & 0,818 \\
\hline Habit & 0,819 \\
\hline Content & 0,803 \\
\hline Behavioral Intention & 0,834 \\
\hline
\end{tabular}

Sumber: Hasil Olahan Penulis (2019)

Setelah melakukan kalkulasi AVE menggunakan software SmartPLS 3.0, maka dapat disimpulkan bahwa seluruh variabel yang ada pada penelitian ini memenuhi kriteria convergent validity, dikarenakan seluruh nilai AVE di setiap variabel bernilai di atas 0,50.

Tabel 2

Nilai CA dan CR Tiap Variabel

\begin{tabular}{|l|c|c|}
\hline \multicolumn{1}{|c|}{ Variabel } & $\begin{array}{c}\text { Cronbach's } \\
\text { Alpha (CA) }\end{array}$ & $\begin{array}{c}\text { Composite } \\
\text { Reliability (CR) }\end{array}$ \\
\hline Behavioral Intention & 0.950 & 0.962 \\
\hline Content & 0.938 & 0.953 \\
\hline Effort Expectancy & 0.924 & 0.942 \\
\hline Falicitating Condition & 0.882 & 0.913 \\
\hline Habit & 0.945 & 0.958 \\
\hline Hedonic Motivation & 0.944 & 0.957 \\
\hline Performance Expectancy & 0.924 & 0.943 \\
\hline Social Influence & 0.939 & 0.954 \\
\hline
\end{tabular}

Sumber: Hasil Olahan Peneliti (2019)

Item dalam penelitian ini, telah memenuhi kriteria realibilitas (reliability), dikarenakan nilai Cronbach's Alpha dan Composite Reliability pada tiap variabel memiliki nilai lebih besar dari 0,7. Berdasarkan seluruh uji yang telah dilakukan, dari validitas dan realibilitas, maka penelitian ini telah memenuhi kriteria yang ditentukan. Maka dari itu, peneliti dapat menarik kesimpulan bahwa seluruh variabel dan indikator dalam penelitian ini valid dan reliable.

\section{Pengujian Model Struktural}

Tabel 3

Path Coefficients dan Nilai $t$

\begin{tabular}{|c|c|c|c|c}
\hline No & Paths & Path Coefficient & Nilai $t$ & Kesimpulan \\
\hline 1 & PE $\rightarrow$ BI & 0.156 & 1.688 & Ha diterima \\
\hline 2 & EE $\rightarrow$ BI & 0.031 & 0.471 & Ha ditolak \\
\hline 3 & SI $\rightarrow$ BI & 0.093 & 1.202 & Ha ditolak \\
\hline 4 & FC $\rightarrow$ BI & 0.158 & 1.78 & Ha diterima \\
\hline 5 & HM $\rightarrow$ BI & -0.25 & 0.351 & Ha ditolak \\
\hline 6 & HT $\rightarrow$ BI & 0.414 & 4.749 & Ha diterima \\
\hline 7 & CT $\rightarrow$ BI & 0.212 & 1.998 & Ha diterima \\
\hline
\end{tabular}

Sumber: Hasil Olahan Peneliti (2019) 
Dalam penelitian ini, peneliti menggunakan siginifikan pada tingkat kepercayaan $95 \%$, dengan menggunakan pengujian one-tailed test. Menurut Abdillah dan Jogiyanto (2009), jika sebuah penelitian menggunakan hipotesis satu ekor (one-tailed test), maka jika nilai t-value $\geq$ 1,68 , dapat disimpulkan bahwa terdapat pengaruh signikan dari variabel independen terhadap variabel dependen, maka dari itu Ha diterima.

Tabel 4

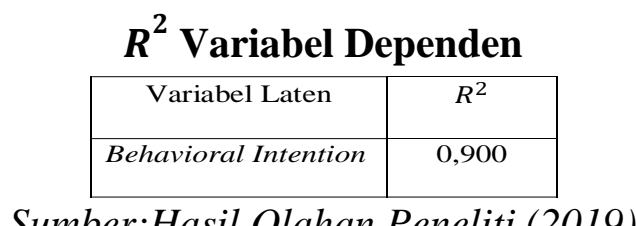

Sumber:Hasil Olahan Peneliti (2019)

Dari nilai $R^{2}$ yang terdapat pada tabel 4 , maka nilai $R^{2}$ pada konstruk variabel dependen Behavioral Intention, adalah sebesar 0,900 yang berarti variabel Behavioral Intention dipengaruhi sebesar 90,0\% oleh variabel Performance Expectancy, Facilitating Conditions, Habit, dan Content, sedangkan pengaruh sebesar 10,0\% dipengaruhi oleh faktor lain, yang tidak diteliti dalam penelitian ini. Hasil $R^{2}$ juga menggambarkan bahwa model terindikasi "Moderat" dikarenakan nilai yang didapat masuk dalam indikasi "Moderat" (Indrawati, 2017:71).

\section{Pengujian Variabel Moderator}

Pada penelitian ini, hanya pengaruh antara variabel content terhadap variabel Behavioral Intention yang tidak dimoderatori oleh variabel gender (Jenis Kelamin). Artinya, Pengaruh Content, Effort Expectancy, Social Influence dan Hedonic Motivations terhadap Behavioral Intention memiliki persepsi yang sama pada pengguna laki-laki ataupun perempuan. Dalam penelitian ini, ditemukan bahwa pengaruh antara variabel Performance Expectancy, Facilitating Conditions, Habit, dan Content terhadap variabel Behavioral Intention dimoderatori oleh variabel Age (Usia). Maka dari itu, dapat diartikan bahwa dalam hal kebiasaan terhadap peminatan penggunaan aplikasi RCTI+, dipengaruhi oleh perbedaan usia.

\section{KESIMPULAN DAN SARAN}

Penilaian konsumen mengenai faktor-faktor yang ada pada model UTAUT2 yang telah dimodifikasi (Performance Expectancy, Effort Expectancy, Social Influence, Facilitating Condition, Hedonic Motivation, Habit, dan Content) pada adopsi penggunaan aplikasi RCTI+ di Indonesia ada pada nilai Tinggi dan 1 variabel yang Cukup Tinggi yakni Habit.

Berdasarkan model UTAUT 2 yang telah dimodifikasi, faktor yang memengaruhi Behavioral Intention konsumen pada penggunaan aplikasi RCTI+ di Indonesia adalah Performance Expectancy, Falicitating Condition, Habit dan Content.

\section{DAFTAR PUSTAKA}

Abdillah, W. \& Jogiyanto. (2015). Partial Least Square (PLS) - Alternatif Structural Equation Modeling (SEM) dalam Penelitian Bisnis. Yogyakarta: ANDI

DailySocial.id. (2018). Video on Demand Survey 2017. Retrieved December 1, 2019, from https://dailysocial.id/post/laporan-dailysocial-survei-video-on-demand-2017 database.

Indrawati, et al. (2017). Materials for Measuring Instant Messenger Application Adoption: Malaysians' Perspective. Switzerland: Trans Tech Publication.

Ulum, M., Tirta, I. M., \& Anggraeni, D. (2014). Analisis Structural Equation Modeling (SEM) untuk Sampel Kecil dengan Pendekatan Partial Least Square (PLS). Retrieved Desember 5, 2019, from http://download. portalgaruda. org/article. php database.

Sugiyono. (2013). Metode Penelitian Manajemen. Bandung: Alfabeta.

Venkatesh, et al. (2012). Consumer Acceptance and Use of Information Technology: Extending the Unified Theory of Acceptance and Use of Technology. Indrawati. (Ed.). Perilaku Konsumen Individu (1st ed.) (pp. 32). Bandung: Refika Aditama. 